\title{
The threat to the universality of science in the post-9/11 world
}

\author{
Asghar Rastegar
}

An eminent Indian scientist is unexpectedly denied a US entry visa because "his research could be used in chemical warfare". Foreign scholars and students face long delays in obtaining US entry visas, resulting in cancelled meetings and loss of scientific opportunities. The Office of Foreign Assets Control (OFAC) of the US Treasury Department tells US publishers that they are in violation of the law if they edit articles or publish books from certain countries. Concern about OFAC rules forces the International Society of Nephrology (ISN) to withdraw funding from an ISN fellow from Iran, and to discontinue its sponsorship of speakers invited to a meeting of the Iranian Congress of Nephrology.

These and other similar events, triggered by the US response to international conflicts and heightened by the 9/11 terrorist attacks, are examples of violations of one of the most cherished principles in science-universality. As articulated by the International Council for Science, "This principle embodies freedom of movement, association, expression and communication for scientists, as well as equitable access to data, information and research materials ... the ICSU actively upholds this principle, and, in so doing, opposes any discrimination on the basis of such factors as ethnic origin, religion, citizenship, language, political stance, gender, sex or age". We, as members of a worldwide scientific community, should take these violations seriously.

The ISN is committed to "excellence in research, education, and patient care in the developed and developing world" and "advancing knowledge across all geographic, national, racial, religious and economic conditions". The Society will "always act in a way that is politically neutral, humanitarian, and culturally diverse". There is, ....violations

of one of the

most cherished

principles

in science

... triggered

by the US

response to

international

conflicts and

heightened

by the $9 / 11$

terrorist

attacks...

\section{A Rastegar is}

Professor of Medicine

(Nephrology) at Yale

University School

of Medicine, New

Haven, CT, USA, and a member of ISN COMGAN's Middle

East committee.

\section{Competing interests}

The author declared he has no competing interests.

www.nature.com/clinicalpractice doi:10.1038/ncpneph0267 therefore, a fundamental conflict between the principle of the universality of science, the mission of the ISN and political realities in the post-9/11 world. How should organizations such as the ISN respond to the rules and regulations that actively impede their work, while remaining within the law and sensitive to national security concerns? I believe such organizations should do the following.

First, educate the public and its representatives about the importance of free exchange of scientific ideas across political boundaries. The ISN, as an international medical organization, should emphasize their responsibility to improve health regardless of nationality, race and religion.

Second, actively engage key individuals in the US State, Homeland Security and Treasury departments in discussion of the purpose and importance of their work, while in turn learning about the security concerns of these government departments.

Third, actively resist rules and regulations that challenge their principles. Faced with such a challenge, international medical organizations should use political and legal channels to defend their position. As an example, the willingness of US publishers to use such channels resulted in marked changes in OFAC rules regarding both editing of articles and publishing of books from embargoed countries.

Finally, organizations such as the ISN should resist the tendency to avoid conflict by overinterpreting the rules. We need to remember that academicians and investigators in embargoed countries work under very difficult conditions, and look to us and our organizations for support. We should at least have the courage to take risks in defense of our principles. 